\title{
NON-AGENDA
}

With the view of causing an increase to take place in the mass of national wealth, or with a view to increase of the means either of subsistence or enjoyment, without some special reason, the general rule is, that nothing ought to be done or attempted by government. The motto, or watchword of government, on these occasions, ought to be - Be quiet. . . Whatever measures, therefore, cannot be justified as exceptions to that rule, may be considered as non-agenda on the part of government.

__ Jeremy Bentham (c.1801)

\section{Does Australia Really Need the ABC?}

\section{Ross Jones}

I

N July 1996, the federal Minister for Communications and the Arts, Senator Richard Alston, announced a review of the role and functions of the Australian Broadcasting Corporation (ABC), the first major review since the 1982 Dix Report. The review, conducted by $\mathrm{Mr}$ Bob Mansfield, released its report, The Challenge of a Better $A B C$, in December 1996. By concentrating on financial issues, however, the review ignored the most important issue: whether there is any need for a publicly funded broadcaster such as the $\mathrm{ABC}$.

\section{Arguments for Public Broadcasting}

The $\mathrm{ABC}$, which receives about $\$ 500 \mathrm{~m}$ annually from taxpayers, has five major official objectives. They are:

1. to be distinctly Australian, developing and enriching a sense of Australian culture;

2. to be an effective and distinctive alternative to other broadcasters by providing a wide range of high quality and innovative services to rural and remote Australia, to the cities and to specialist and minority audiences;

3. to provide Australians with independent coverage and analysis of contemporary issues and events;

Ross Jones is Senior Lecturer in Economics at University of Technology, Sydney. 
4. to achieve the most cost-effective use of its resources; and

5. to employ and develop new technologies and techniques that will improve service and efficiency (DTC, 1992).

These objectives reflect the widespread beliefs that only tax-financed public broadcasting is capable of providing quality programs, and that, without it, consumers would face a limited choice of programs. In particular, it is believed in many English-speaking countries that popular broadcasting by advertiser-financed commercial channels must inevitably be dominated by American products at the expense of local culture and to the detriment of national identity. The argument goes that commercial broadcasters provide programs free to consumers and are therefore unable to measure the intensity of demand for particular types of programs by consumers' willingness to pay. Consequently, they always give priority to maximising their audience and so tend to produce the same types of programs (such as news and current affairs and sport) and to show them at the same times. Correspondingly, they have little incentive to provide programs which attract minority audiences, thus failing to meet audience demands for a greater diversity of programming.

Such market failure can allegedly be corrected by the diverse range of programming made available by public broadcasters, a range far beyond that provided by private broadcasters. This diversity also promotes the preservation and enhancement of a national culture and identity. Although commercial broadcasters may provide news, current affairs, sport and quiz show programs with a strong domestic content, they are less likely to provide indigenous drama programming given its relatively high cost and the low price of imported, especially American, drama. Hence, it is argued, taxpayer-funded public broadcasting is justified on cultural as well as economic grounds.

\section{Does the Market Fail?}

But does the broadcasting market fail in this way? And, if so, why?

It seems plausible to argue that Australia's three commercial television networks do not provide as diverse a range of programming as may be demanded. As their critics point out, they provide similar types of broadcasting and schedule them at similar times. Yet a very diverse range of commercial radio programs is available in Australia. This difference between radio and television in terms of content diversity reflects different degrees of market competition: whereas many commercial radio channels exist, there are only three commercial television broadcasters, each of which has to try to achieve the maximum audience size by providing programs that appeal to the majority. In this sense, the provision of more diversified services by a public broadcaster may be justified.

However, the oligopolistic market structure of Australian commercial television is a consequence of government regulation. It is more than 30 years since the third commercial network (Ten) was licensed to operate in Australia's major cities. Few 
other industries have received such protection from governments against new competition. Yet in many cities around the world with markets the size of Sydney's and Melbourne's, many competing commercial broadcasters exist, both free-to-air and, more recently, pay TV. But in Australia, the three existing commercial networks have for many years successfully lobbied governments to prevent new free-to-air and pay TV services.

The introduction of pay TV and new digital technology is likely to have profound effects on both commercial television stations and public broadcasters. Already pay TV is providing a diverse range of channels, with dedicated movie, sport, children's and documentary channels. Internationally, a vast range of minority interest channels is available and is likely to become available in Australia in the next few years. Some of these channels may be little more than repackaged library material from foreign production companies; yet consumers appear to value them sufficiently to pay for them. While some critics of pay TV have claimed that it provides ' 57 channels and nothin' on' (to quote Bruce Springsteen, 1992), such claims merely reflect the bias of these critics rather than providing a justification for the public provision of 'quality' programming.

Digitalisation may make possible the entry of more free-to-air broadcasters if the government refuses the demands of the existing commercial networks to be allocated the additional spectrum freed up by digitalisation. As the number of channels increases, diversity will expand rapidly. Consequently, the argument that a public broadcaster such as the $A B C$ is necessary to provide diversity will become increasingly irrelevant as commercial channels compete against each other by offering a greater range of program choices.

\section{High-Quality Services}

Arguments that the $\mathrm{ABC}$ is necessary to provide 'quality' are similarly undermined by the greater available choice. The claim that a public broadcaster should provide 'superior' programs to those that viewers might otherwise choose is patronising and elitist. The most effective way to encourage consumers to widen their programming tastes is to provide a wide range of choice, something subscription television can do more effectively than a single-channel public broadcaster. The wide range of cuisines now available in Australian restaurants is evidence of way in which unrestricted competition encourages experimentation and diversity.

A related argument is that public broadcasting is needed because consumers have insufficient information about program content and quality to make informed choices. But many entertainment services suffer from an 'information failure' problem. Consumers are typically not fully aware of the quality of a movie or a play or a concert before they buy the service; but the suppliers survive without subsidies such as those given to public television.

In numerous other information and entertainment industries, competitive private companies provide quality and diversity. For example, it is rare to hear the claim that Australia needs publicly funded newspapers and magazines to ensure quality. Australia also has a number of quality newspapers which do not need pub- 
lic funding and ownership to survive. Indeed, publicly funded broadcasters such as the $\mathrm{ABC}$ may hinder the development of quality and diversity. The provision of broadcast services at no direct cost to the viewer may be a major barrier to the entry of new competing commercial services. Just as a publicly funded quality newspaper would put in doubt the viability of a number of Australia's quality newspapers, the 'free' $\mathrm{ABC}$ will probably inhibit the development of wide range of quality television channels in the future.

As well, the diversity offered by public broadcasters may not necessarily reflect consumer demand. Just as in a centrally planned economy the planners often make inaccurate demand and supply forecasts, so may public broadcasters. Their programs may reflect the interests and opinions of those who spend the public money rather than of the taxpayers and viewers who supply it. And while public broadcasters may provide greater diversity than a small number of commercial free-to-air broadcasters can, they have neither the financial resources nor the channel capacity to provide the diverse range of programming available from subscription television.

One area where market failure may justify some form of intervention is children's programming. Children may not be aware of the benefits of education and the merit in consuming educational programs. Further, even if they were aware of benefit, they are unlikely to have the direct purchasing power to convey their demands for programs to producers and broadcasters. However, this consideration is insufficient to justify the existence of public broadcasters such as the $A B C$ : quotas for children's programs on commercial networks together with subsidies for the production of programs with educational merit may be a more efficient mechanism.

\section{Independent Coverage?}

The claim that the $\mathrm{ABC}$ provides independent and unbiased coverage of news and current affairs is also open to debate. News and current affairs on public broadcasters may not be subject to the influence of a proprietor, but it may nevertheless reflect the views of its 'owner', in this instance the government, particularly when the government provides the public broadcaster with its income. On numerous occasions, the $\mathrm{ABC}$ has been accused of bias in its news reporting. But news reporting may often reflect the bias of the reporter rather than the media owner. The most effective way to counter any perceived bias is to ensure that a diverse range of information sources is available.

Given the prestige, influence and reputation for independence that is traditionally associated with national broadcasters, the possibility of bias in the news reporting of the $\mathrm{ABC}$ is of greater concern than in the case of private sector organisations. But the ability of new technology such as pay TV and digitalisation to provide a range of channels and consequently a range of reporter viewpoints may be the most effective answer to the problem. A number of such sources now provide a range of current affairs and business channels offering a range of views: While these sources are typically foreign rather than Australian, future expansion of pay TV channels may provide a greater range of domestic as well as foreign perspectives 
on news and current affairs should consumers value such choices sufficiently to be prepared to pay for them.

\section{Public Broadcasting Objectives Revisited}

There is, then, little justification for continued taxpayer funding of public broadcasting on the grounds of market failure. But even if such justification did exist, the question remains whether Australia's public broadcasters meet their official objectives.

One of the ABC's stated objectives is to develop a sense of Australian culture. It appears to have had little success. The Mansfield Report (1997:36) notes that, in 1995 and the first half of 1996 , no Australian drama or comedy program was among the 20 most popular ABC programs. By contrast, seven British drama and comedy programs were among the top 20 . Audiences for $\mathrm{ABC}$ coproductions were found to be on average 25 per cent higher than for in-house productions. This suggests that the $\mathrm{ABC}$ was not particularly adept at producing Australian programs that Australians wanted to see. But if the $\mathrm{ABC}$ is to develop a sense of Australian culture, people at least need to be watching its programs.

Arguably, the commercial networks are better at meeting this cultural objective. The commercial networks are subject to rigorous Australian content requirements: the Australian Broadcasting Authority requires that 50 per cent of all programs broadcast between $6 \mathrm{am}$ and midnight must be Australian-made. The most popular Australian programs are broadcast by commercial stations. Perhaps the cultural objectives should be left to the commercial networks.

A recent analysis by the Bureau of Transport and Communications Economics (1996) of the community benefits of Australian television programming and regulation found that Australians were dissatisfied with the mix of Australian programming; substantial unmet demand existed, for example, for documentaries and children's programs, whereas drama series and serials were oversupplied. The ABC does not appear to be programming to meet such stated demands.

The commitment of the $\mathrm{ABC}$ to another of its objectives - regionalism in broadcasting - was also questioned by the Mansfield Report (Mansfield, 1997:24). The $\mathrm{ABC}$ has in recent years reduced State-based programming on television and (to a lesser extent) on radio. The Report notes that the $A B C$ could not reflect the plurality of Australian views if it operated only from the capital cities.

Australia's other publicly funded broadcaster, Special Broadcasting Services (SBS), has similarly failed to meet its objectives. Launched in 1980, SBS television was designed to provide an 'ethnic' multicultural television service. However, SBS television, which several years ago started accepting advertising, now proclaims itself to advertisers as providing a unique marketing audience. 'They are the A-B audience, highly educated, very selective, very independent', according to the head of SBS marketing (The Bulletin, 8 October 1996). The average taxpayer, it appears, is subsidising the viewing habits of a wealthy section of the population: a damaging admission for a public broadcaster. The typical SBS audience would appear to be precisely that which should be served by a quality commercial subscription service. 


\section{The Future of Public Broadcasting}

If the traditional arguments for public broadcasting ever had much weight, they certainly do not nowadays. Technological developments have led to an enormous expansion of capacity, and enable service providers to charge consumers directly for programming. Consequently, a huge range of programs can be supplied to consumers, and such programs will reflect consumer demand.

As subscription television grows, the demand for public broadcasting services is likely to decline. Faced with dwindling audience share, public broadcasters may become expensive marginal anachronisms. A logical response would be to move towards privatisation. SBS is an obvious and immediate candidate for privatisation. It would function successfully as a private subscription network. It already provides (with pay-TV partners) subscription television. There is also scope for the $\mathrm{ABC}$ to provide a range of subscription channels. The British Broadcasting Corporation has already launched similar ventures. Digitalisation of free-to-air broadcasting over the next few years could provide the $\mathrm{ABC}$ with the option of supplying subscription services which meet consumer demand.

However, taxpayers would not need to fund such services. The most important role for government in broadcasting is to enforce strong competition laws. The government should ensure that opportunities exist for new firms to enter the media markets, and that no firm can gain or maintain excessive market power. To this end, privatisation of SBS and ABC, new free-to-air licences for digital broadcasters, and an open-access regime for cable and satellite delivery would more effectively achieve the objectives of diversity and high quality in programming.

\section{References}

Bureau of Transport and Communications Economics (1996), Measuring Community Benefits of Australian TV Programs, AGPS, Canberra.

Committee of Review of the Australian Broadcasting Commission (1981), The ABC in Review: National Broadcasting in the 1980's (A .T. Dix Chairman), AGPS, Canberra.

Department of Transport and Communications (DTC) (1992), Portfolio Program Performance Statements 1992-93, AGPS, Canberra.

Mansfield, B. (1997), The Challenge of a Better ABC. Vol I: A review of the role and functions of the $A B C$, AGPS, Canberra.

Springsteen, B. (1992), '57 Channels (And Nothin' On)', Human Touch, Sony Music, New York. 